Preprints of the

Max Planck Institute for

Research on Collective Goods

Bonn 2014/14

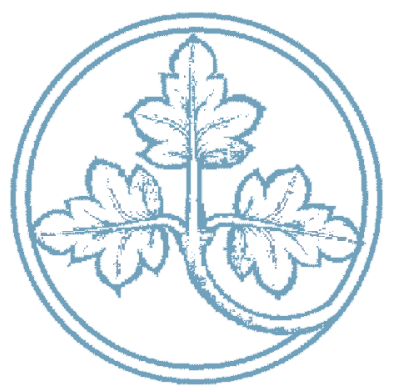

Outside Liquidity, Rollover

Risk, and Government Bonds

Stephan Luck

Paul Schempp

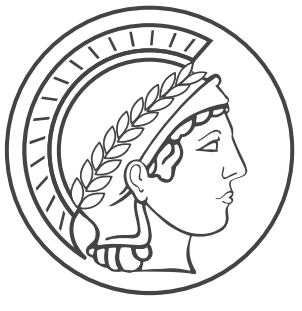




\title{
Outside Liquidity, Rollover Risk, and Government Bonds
}

\author{
Stephan Luck / Paul Schempp
}

September 2014 


\title{
Outside Liquidity, Rollover Risk, and Government Bonds*
}

\author{
Stephan Luck ${ }^{\dagger}$ and Paul Schempp ${ }^{\ddagger}$
}

This paper discusses whether financial intermediaries can optimally provide liquidity, or whether the government has a role in creating liquidity by supplying government securities. We discuss a model in which intermediaries optimally manage liquidity with outside rather than inside liquidity: instead of holding liquid real assets that can be used at will, banks sell claims on long-term projects to investors. While increasing efficiency, liquidity management with private outside liquidity is associated with a rollover risk. This rollover risk either keeps intermediaries from providing liquidity optimally, or it makes the economy inherently fragile. In contrast to privately produced claims, government bonds are not associated with coordination problems unless there is the prospect that the government may default. Therefore, efficiency and stability can be enhanced if liquidity management relies on public outside liquidity.

Keywords: liquidity provision, liquidity mismatch, bank run, roll-over freeze, outside liquidity, government bonds, liquidity regulation JEL codes: G21, G28, H63, H81

\footnotetext{
${ }^{*}$ We are especially thankful for Martin Hellwig's extensive advice and support. Moreover, we thank Brian Cooper, Christoph Engel, Falko Fecht, Christian Hellwig, Konstantin Milbradt, Alexander Morell, and participants at the EDP Jamboree 2013 in Brussels for valuable comments. Financial support by the Alexander von Humboldt Foundation is gratefully acknowledged.

†luck@coll.mpg.de, University of Bonn and Max Planck Institute for Research on Collective Goods.

${ }^{\ddagger}$ schempp@coll.mpg.de, University of Bonn and Max Planck Institute for Research on Collective Goods.
} 


\section{Introduction}

Empirical evidence suggests that investors value the liquidity of government bonds (see, e.g., Longstaff, 2004, Krishnamurthy and Vissing-Jorgensen, 2012). There are various explanations for why incomplete financial markets and financial frictions give rise to a demand for liquidity, and for government securities as means to provide such liquidity. Government bonds may be valuable to investors as a simple medium of transfer across time, e.g., to enhance risk-sharing (see, e.g., Gale, 1990) or to improve investment by alleviating frictions (see, e.g., Woodford, 1990, Saint-Paul, 2005). Demand for government securities may especially arise when private liquidity provision is limited, e.g., if moral hazard and commitment problems restrict the pledgeable income of private agents. Publicly issued claims may guarantee the provision of liquidity and reduce the need to set liquid real assets aside (Holmström and Tirole, 1998, 2011). Moreover, it lies in the nature of government bonds that they mitigate the adverse selection problems typically associated with liquidity provision because they are free from private information (Gorton and Pennacchi, 1990; Gorton and Ordoñez, 2013).

This paper provides a simple but novel explanation for why government securities are especially suited to manage liquidity needs: government securities are less prone to coordination failures than privately issued claims, i.e., less exposed to rollover risk.

In the run-up to the recent financial crisis, financial intermediaries satisfied liquidity needs by transforming long-term real investments into liquid claims instead of setting liquid real assets aside. However, when the crisis unfolded as a consequence of various shocks in the housing market, privately produced assets stopped being liquid - leaving financial markets and intermediaries in turmoil. 1 The crisis ultimately appears as an inability of the private sector to provide liquidity efficiently to the economy.

In our model, financial intermediaries ${ }^{2}$ optimally provide liquidity not through holding liquid real assets that can be used at will (inside liquidity). Instead, they optimally rely on liquidity that investors provide in exchange for claims on future returns of long-term real investments (referred to as private outside liquidity). The key friction of our model is that at the time of initial investment, it impossible to contract with the potential providers of private outside liquidity such as wholesale funding. While the reliance on outside liquidity increases profitable long-term investment, it may be also associated with a rollover risk. We argue that this rollover risk is inherent in liquidity management with privately produced claims. We show that the rollover risk may either make intermediaries refrain from providing liquidity optimally in the first place, or it may make the economy

\footnotetext{
${ }^{1}$ See, e.g., Hellwig (2008), Brunnermeier (2009), Krishnamurthy (2010), and Caballero (2010).

${ }^{2}$ We use the terms "bank" and "financial intermediary" interchangeably throughout the paper.
} 
inherently fragile. In turn, under the assumption that the government never defaults, public claims are free from such risk. Satisfying liquidity needs by selling government securities in exchange for outside liquidity (referred to as public outside liquidity) may thus enhance efficiency and stability.

We derive our results from a banking model in the tradition of Diamond and Dybvig (1983, henceforth D\&D). Demand for liquid assets arises from an idiosyncratic liquidity risk on the part of consumers. Financial intermediaries provide optimal risk-sharing to consumers by offering demand-deposit contracts. However, we alter the D\&D setup by assuming that banks can sell claims on their future returns to investors in the interim period in exchange for outside liquidity. Banks use the proceeds to serve early withdrawing consumers. This model feature is reminiscent of Holmström and Tirole 1998 , 2011) and Bolton et al. (2011).

The model's implications are the following: First, the presence of investors who may buy claims on future returns generally allows a reduction of the holdings of liquid real assets in order to manage liquidity. Banks can conduct more productive, but illiquid long-term investments. Second, we find that intermediaries might not be able to manage liquidity optimally with privately produced claims. Relying on outside liquidity by investors in exchange for privately produced claims exposes an intermediary to the risk of a rollover freeze. There is strategic complementarity between investors in their decisions to purchase claims on intermediaries' future returns. If no investor purchases claims, the intermediary will be forced to conduct costly liquidation. This in turn may make it optimal to refuse a rollover. Importantly, the rollover risk - unlike the classical bank run problem - cannot be eliminated by a classic deposit insurance or by a suspension of convertibility. This caused by the friction that outside liquidity is not contractible in the initial period. The potential rollover freeze in turn may make intermediaries either reluctant to implement the first-best, or it may make the economy inherently fragile.

As a third result, we show that in the presence of potential coordination failures between investors, the existence of public claims increases welfare. These claims allow intermediaries to implement the optimal allocation without exposing the economy to the risk of a rollover freeze. The reason is simple: under the assumption that the government never defaults, government securities are never subject to a coordination problem, i.e., there is no strategic complementarity between the investors in their decisions to purchase government bonds. In contrast to privately produced assets, the value of government securities is independent of the decision of investors to purchase the security or not. By using government bonds to manage liquidity, banks can reduce inefficient reliance on inside liquidity while avoiding rollover risk. Consequently, government borrowing may 
have non-Ricardian effects (see, e.g., Barro, 1974).

Finally, we discuss the assumption that the government can always repay its debt. We show that once the government's ability to repay depends on the banking sector, a run on the banking sector may be complemented by a run on government debt if there is public supply of liquidity. In this case, the positive effects of public liquidity provision may vanish. We analyze the interplay of sovereign defaults and banking crises in more depth in a companion paper (Luck and Schempp, 2014b).

We use the term "outside liquidity" in the sense of Holmström and Tirole (2011), Bolton et al. (2011), and Gourinchas and Jeanne (2012). The concept of inside and outside liquidity is to some degree reminiscent to the definition of inside and outside money (see, e.g., Lagos, 2006), but there are subtle differences. Outside money is money that is not anyone's liability, and that is thus a net asset for the private sector. In contrast, inside money is created within the private sector, and is thus some private agent's liability. Similarly, inside liquidity is the liquidity that is created within a specified sector, while outside liquidity is supplied by agents or institutions outside this sector. In contrast to the definition of outside money, outside liquidity is mostly defined "from the point of view of the financial sector" 3 In Bolton et al. (2011), inside liquidity denotes the intermediary's cash reserves, whereas the intermediary can raise outside liquidity by selling assets to long-term investors (hedge funds and pension funds). Thus, outside liquidity is the label for liquidity that investors supply to banks (and thus to consumers).

This paper is closely related to the literature on the government's role in providing safe assets for the purpose of liquidity management. As in the seminal paper by Holmström and Tirole (1998), we allow the economy to reduce the holdings of real assets and to issue claims on future returns in order to manage liquidity needs. In contrast to Holmström and Tirole, the limitation of private liquidity supply originates not from agency problems, but from coordination problems. In terms of our results, this paper is close to a series of recent papers (Greenwood et al., 2012; Gourinchas and Jeanne, 2012; Gorton and Ordoñez, 2013). With Gorton and Ordoñez (2013), we share the notion that government bonds are more liquid than privately produced assets and make the economy more stable. However, their reasoning is based on the information sensitivity of assets 4 They show that liquidity provision by privately produced assets may make an economy fragile, as seemingly safe assets may become illiquid when they become information-sensitive. Government bonds in turn are less information-sensitive and thus more liquid. With the paper by Greenwood et al. (2012) we have in common that the government has a

\footnotetext{
${ }^{3}$ Definition in Gourinchas and Jeanne (2012); other definitions are similar.

${ }^{4}$ See Dang et al. (2013a) and Dang et al. (2013b) on information (in)sensitivity of assets and financial crises.
} 
comparative advantage in bearing refinancing risk relative to the private sector, and thus public provision of liquidity is welfare-enhancing. However, their focus is on the maturity of different securities. Finally, Gourinchas and Jeanne (2012) provide a macroeconomic model with inside and outside liquidity. As in our setup, a crisis occurs when private liquidity provision is insufficient and the role of public securities for financial stability is emphasized.

Our paper can also be interpreted in the light of the theory of liquidity mismatch. Brunnermeier et al. (2013) argue that maturity transformation and the associated maturity mismatch are not problematic per se. Fragility arises only if maturity transformation also induces a liquidity mismatch. While financing a 20 year government bond with demand deposits is an extreme form of maturity mismatch, it does not constitute a liquidity mismatch as long as there is a liquid market for government bonds. In our model, the government bonds on the banks' balance sheets neither change the mechanism of maturity transformation nor the liquidity mismatch, but it substantially reduces the liquidity mismatch.

We also relate our results to recent empirical findings. In our model, liquidity benefits from government bonds have real effects, consistent with the evidence that investors value these attributes (Krishnamurthy and Vissing-Jorgensen, 2012). Moreover, public provision of liquidity reduces the fragility in our setup, which is in line with the finding that financial crises are more likely when little public debt is available (Krishnamurthy and Vissing-Jorgensen, 2013) and financial crises seem to be related to excessive private debt rather than public debt (Jordà et al., 2013; Schularick, 2014).

The paper is also very closely related to theories of banking, in which intermediaries optimally rely less on inside liquidity and more on sales of claims on long-term investments, such as the model by Bolton et al. (2011). This model is concerned with the timing of trade in the presence of uncertainty and asymmetric information, while we focus on the coordination failures that may be associated with outside liquidity.

Finally, our paper contributes to the literature on liquidity provision by financial intermediaries. D\&D have argued that financial intermediaries can provide optimal risksharing to consumers and allow them to benefit from profitable long-term investments by offering demand-deposit contracts $5^{5}$ In contrast, we argue that the ability of financial intermediaries to provide liquidity is limited. We are far from being the first to address the problems of liquidity provision by intermediaries. The banking literature has already produced various arguments. It has been argued that the ability of banks to provide risk-

\footnotetext{
${ }^{5}$ On the optimality of intermediaries of liquidity provider, see also, e.g., Gorton and Pennacchi (1990), Calomiris and Kahn (1991), Diamond and Rajan (2001), and Kashyap et al. (2002).
} 
sharing in the presence of financial markets is very limited (Jacklin, 1987, Farhi et al.,


may be harmed (von Thadden, 1998). Moreover, banks may be unable to implement the first-best through demand-deposit contracts in the presence of macroeconomic interest rate risk (Hellwig, 1994) 7 Under aggregate risk and in the presences of moral hazard, financial intermediaries may not be able to insure firms against liquidity shocks either (Holmström and Tirole, 1998). The creation of liquidity through interbank trade may also be limited if banks are unable to diversify the liquidity risk of their consumers (Bhattacharya and Gale, 1987).

Our argument, however, is neither based on agency problems nor on aggregate uncertainty. We argue that liquidity management with privately issued claims creates a coordination problem between those investors who could provide liquidity. A memorable insight from the seminal contributions by Bryant (1980) and D\&D is that liquidity provision may be associated with the existence of run equilibria and make an economy inherently fragile 8 Importantly, the rollover problem in our setup differs from the classical bank run problem. We show that the coordination problem cannot be eliminated by a deposit insurance nor by a suspension of convertibility. Ultimately, the rollover risk associated with optimal private liquidity provision may prevent the implementation of the optimal allocation in the first place. Our paper stands in contrast to models arguing that banks are especially suited to provide liquidity because of their fragile capital structure. Amongst others, Calomiris and Kahn (1991) and Diamond and Rajan (2001, 2005 argue that the fragile nature of bank balance sheets disciplines bank managers and thus allows overcoming commitment problems associated with liquidity provision. In contrast, we argue that the potential rollover risk may cause banks to refrain from supplying liquidity in an optimal fashion in the first place.

We proceed as follows: In Section 2, we introduce the general setup and derive the first-best allocation and show how it can be implemented by banks. In Section 3, we investigate how the first-best and its implementation change if we introduce outside liquidity. Section 4 shows how the rollover risk associated with privately liquidity supply influences the stability and efficiency of banks. In Section 5, we demonstrate why the

\footnotetext{
${ }^{6}$ See also Diamond $(1997)$ and Fecht $(2004)$.

${ }^{7}$ See also Allen and Gale $(1998)$ on this point.

${ }^{8}$ Following the seminal contributions by Bryant and Diamond and Dybvig, a vast literature on bank runs evolved. See, e.g., the literature regarding information-based runs (Jacklin and Bhattacharya, 1988), models with positive probability of bank runs (Postlewaite and Vives, 1987; Chari and Jagannathan, 1988 Allen and Gale, 1998, Rochet and Vives, 2004, Goldstein and Pauzner, 2005), models with interbank contagion (Allen and Gale, 2000, Dasgupta, 2004 Uhlig, 2010), runs in repurchase agreements (Martin et al., 2014), and dynamic runs (He and Xiong, 2012).
} 
provision of public liquidity by the government is superior to the private case. Finally, we use our model to evaluate the liquidity regulation proposed in Basel III in Section 6 .

\section{Intermediation with Inside Liquidity}

Consider an economy that goes through a sequence of three dates, $t \in\{0,1,2\}$. There is a single good that can be used for consumption as well as for investment. Moreover, there are two investment technologies that we refer to as assets. The economy is populated by risk-averse consumers who face an idiosyncratic liquidity risk.

\section{Consumers}

There is a continuum of ex ante identical consumers with mass one. Each consumer is endowed with $e_{0}$ units of the good in $t=0$. There are two types of consumers, denoted by $\theta_{i} \in\{0,1\}$. The type determines the consumer's intertemporal preference for consumption in periods one and two. With probability $\pi$, consumer $i$ is an "impatient consumer" who needs to consume in $t=1$, denoted by $\theta_{i}=1$. With probability $(1-\pi)$, she is a "patient consumer" who is indifferent between consumption at both dates, denoted by $\theta_{i}=0$. Initially, consumers do not know their type; their probability of being type 1 is identical and independent. In period one, each consumer privately learns his type. This private revelation can be considered as a liquidity shock.

A consumption profile $\left(c_{1}, c_{2}\right)$ gives a consumer $i$ a utility of

$$
U\left(c_{1}, c_{2}, \theta_{i}\right)=\theta_{i} u\left(c_{1}\right)+\left(1-\theta_{i}\right) u\left(c_{1}+c_{2}\right)
$$

where the "baseline" utility $u: \mathbb{R}^{+} \rightarrow \mathbb{R}$ is an increasing and strictly concave function that is twice continuously differentiable and satisfies Inada conditions, $u^{\prime}(0)=+\infty$ and $u^{\prime}(+\infty)=0$. For each consumer, the ex-ante expected utility is given by $\mathrm{E} U\left(c_{1}, c_{2}\right)=$ $\pi u\left(c_{1}\right)+(1-\pi) u\left(c_{1}+c_{2}\right)$.

Notice that the attributes "patient" and "impatient" characterize the consumer's exogenous type which determines his preference, denoted by $\theta_{i}$. In contrast, the attributes "late" and "early" will characterize the timing of consumption which is endogenous: An "early consumer" consumes in $t=1$, while a "late consumer" consumes in $t=2$.

\section{Assets}

There are two different assets (investment technologies) available in $t=0$ : a short asset (storage technology), and a long asset (production technology). The short asset transforms one unit of the good at time $t$ into one unit of the good at $t+1$, effectively storing the good. The long asset promises a higher expected return in the long run. 
However, this asset is considered to be illiquid as it can only be liquidated with a substantial discount in $t=1$.

The long asset is represented by a continuum of investment projects. An investment project is a metaphor for an entrepreneur who is endowed with a production technology but has no endowment of goods for investment. Each consumer has access to exactly one project (or equivalently is matched with exactly one entrepreneur). Each investment project yields a stochastic return of $R_{i}$ units in $t=2$ for each unit invested in $t=0$. The return $R_{i}$ is the realization of an independently and identically distributed random variable $\tilde{R}$, characterized by a probability distribution $F$. F is continuous and strictly increasing on a compact interval with minimum $\underline{R}>0$ and maximum $\bar{R}$, with $\mathrm{E}\left[R_{i}\right]=$ $R>1$. We assume that the realization of an investment project's long-term return $R_{i}$ is privately revealed to the project's financier in $t=1$. As we will shortly see, the idiosynchratic risk implies that financial intermediaries dominate a financial markets solution in terms of welfare.

Finally, an investment project may be physically liquidated prematurely at a rate $\ell \in(0,1 / R)$ in $t=1$, yielding a liquidation return of $\ell R_{i}$ units. The liquidation return of a project thus depends on the project's stochastic long-term return. However, the ratio of liquidation return to long-term return is constant and equal to $\ell$.

\subsection{First-Best Allocation}

The allocation of consumption across different consumer types and different periods is denoted by $\left\{c_{1}(\theta), c_{2}(\theta)\right\}_{\theta \in\{0,1\}}$. The unconstrained optimum results from the social planner's first-best problem, which is given by

$$
\max _{\left\{c_{1}(\theta), c_{2}(\theta)\right\}_{\theta \in\{0,1\}}} \pi u\left(c_{1}(1)\right)+(1-\pi) u\left(c_{1}(0)+c_{2}(0)\right)
$$

subject to

$$
\pi\left(c_{1}(1)+\frac{c_{2}(1)}{R}\right)+(1-\pi)\left(c_{1}(0)+\frac{c_{2}(0)}{R}\right) \leq e_{0} .
$$

Equation (3) is the feasibility condition, resulting from the initial investment constraint in $t=0$ and the two budget constraints in period one and two.

In the first-best, it holds that

$$
c_{2}(1)=c_{1}(0)=0
$$

The late consumption levels of patient and the early consumption level of impatient 
consumers are then given by the following first-order condition and budget constraint:

$$
\begin{gathered}
u^{\prime}\left(c_{1}(1)\right)=R u^{\prime}\left(c_{2}(0)\right), \\
\pi c_{1}(1)+(1-\pi) \frac{c_{2}(0)}{R}=e_{0} .
\end{gathered}
$$

The optimal allocation is thus characterized by the trade-off between insurance against liquidity risk (investment in storage) and productive investment (investment in the longassets).

\subsection{Diamond \& Dybvig (1983)}

The model described above resembles the essential features of the framework of the D\&D model. Therefore, we briefly review the key results of the seminal D\&D model. The first important result is that a competitive financial market generally fails to implement the first-best allocation. In contrast, a competitive banking sector or a representative bank can implement the first-best. It is assumed that the law of large numbers applies on the bank level. That is, there is neither uncertainty on the fraction of consumers being impatient, $\pi$, nor on the return of the portfolio of long assets, $R$.

A bank that aims at maximizing consumers' expected utility thus needs to maximize (2) subject to the feasibility constraint, and because the type of consumers is private information, the constrained efficient program contains two additional restrictions. The allocation of consumption must be such that no consumer has an incentive to misreport his type in the interim period:

$$
\begin{aligned}
u\left(c_{1}(1)\right) & \geq u\left(c_{1}(0)\right), \\
u\left(c_{1}(0)+c_{2}(0)\right) & \geq u\left(c_{1}(1)+c_{2}(1)\right) .
\end{aligned}
$$

Constraint (7) ensures that a impatient consumer has no incentive to misreport, while (8) ensures that a patient consumer does not want to misreport. Adding constraints (7) and (8) to the first-best problem, however, does not change the solution because the constraints are not binding in the first-best. This implies that the first-best is in fact implementable given the friction of unobservable types. The second-best thus coincides with the first-best.

The proposed mechanism, a bank representing a contestable banking sector, proceeds as follows (see also Figure 1): In $t=0$, the endowment of all consumers is collected. In exchange the bank offers a demand-deposit contract that allows a consumer to withdraw $c_{1}^{*}$ units in $t=1$ and $c_{2}^{*}$ units in $t=2$. The bank chooses $c_{1}^{D D}$ and $c_{2}^{D D}$ such that $u^{\prime}\left(c_{1}^{D D}\right)=R u^{\prime}\left(c_{2}^{D D}\right)$ which is the FOC for the first-best allocation, see Equation (5). 


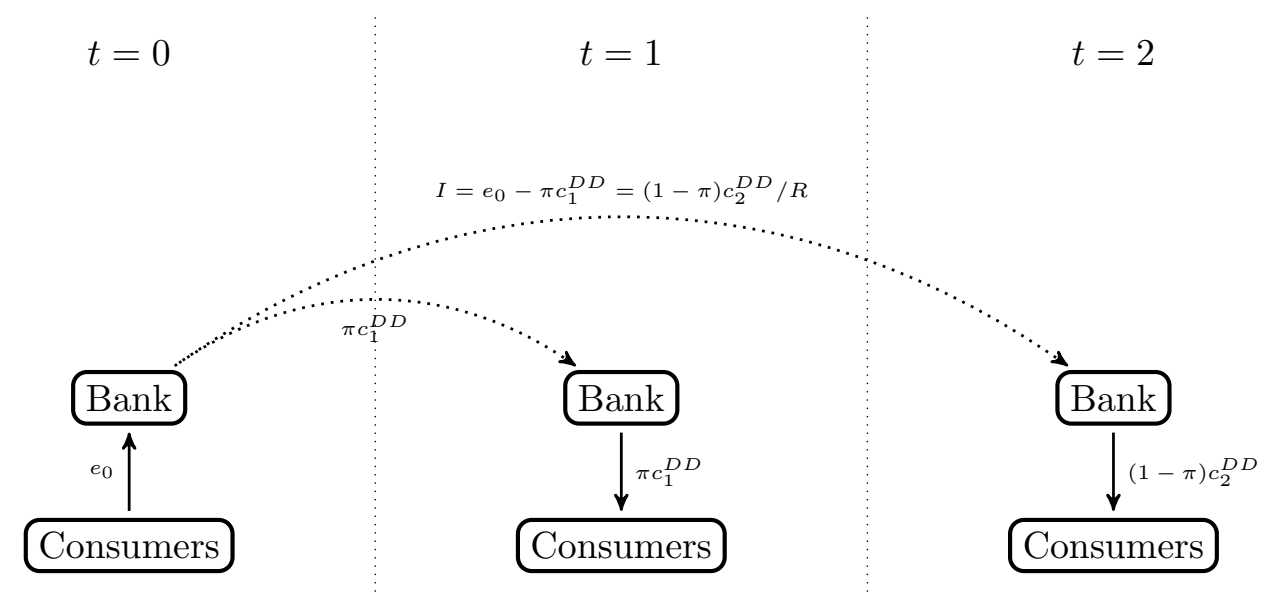

Figure 1: Diamond and Dybvig (1983). The graph illustrates investment and the flow of goods (solid arrows). Initially, consumers deposit their endowment at the bank. Banks invest the endowment in the long and in the short asset. In periods one and two, early and late consumers are served with the returns of the short and the long asset, respectively.

$R>1$ and concavity of $u$ imply that $c_{1}^{D D} \leq c_{2}^{D D}$, and thus Equations (7) and (8) are satisfied and it is incentive-compatible for patient consumers to withdraw only in $t=2$. The bank invests $e_{0}-I=\pi c_{1}^{D D}$ in the storage technology and the remaining funds $I=e_{0}-\pi c_{1}^{D D}$ in the long asset, which implies that Equation (6) holds. The representative bank is thus able to implement the first-best allocation.?

The second important result is that there is also a second type of equilibrium in $t=1$. If all patient consumers desire withdrawing at once, the bank will be left with assets of $\pi c_{1}^{D D}+\ell\left(1-\pi c_{1}^{D D}\right)<1$ which is typically strictly less than its total liabilities in $t=1$, which amount to $c_{1}^{D D} 10$ The bank will therefore be insolvent in $t=1$ and no funds for patient consumers will be left over in $t=2$. It is thus optimal for all patient consumers to withdraw and a bank run may constitute an equilibrium in the interim period. In fact, there are two subgame-perfect Nash-Equilibria in $t=0$, one in which the bank is established, and a second one in which consumers refuse to deposit funds in the banks as they expect a bank run in $t=1$.

Finally, the third result of the D\&D model is that the adverse run equilibrium can

\footnotetext{
${ }^{9}$ Note that the optimality of the banking solution relies on a no-trading restriction of consumers in $t=1$; see Jacklin (1987) and more recently Farhi et al. (2009).

${ }^{10}$ The run equilibrium exists whenever $c_{1}^{D D} \geq 1$. This condition is typically satisfied through the assumption that the coefficient of relative risk-aversion is larger than one, i.e., $-c u^{\prime \prime}(c) / u^{\prime}(c)>1$ for every $c$.
} 
be eliminated by two policy measures: either the banks should commit to suspending convertibility after paying out an overall amount of $\pi c_{1}^{D D}$, or the government should provide a deposit insurance which guarantees $c_{1}^{D D}$ units for each consumer in $t=1$, irrespective of the banks being solvent or not. In both cases, the adverse equilibrium can be eliminated at no cost 11

\section{Intermediation with Outside Liquidity}

We now introduce a new type of agents whom we refer to as "investors". Investors can provide banks or consumers with liquidity in the interim period which we refer to as "outside liquidity". In the following, we analyze how the optimal allocation is altered by allowing for interim outside liquidity, and how the new first-best allocation may be implemented by a banking sector.

Assume that there is a continuum of investors with mass $\alpha>1$. Investors have no endowment initially, but with a probability $1 / \alpha$ an investor $j$ has an endowment of $e_{1, j}=$ $e_{1}$ in period one. Otherwise, her endowment is zero. Therefore, the mass of investors that has a positive endowment is equal to one, and the overall endowment of all investors is $e_{1}=\int e_{1, j} \mathrm{~d} j$. We assume that $e_{1}>\pi R e_{0}$. As we will see, this condition assures that the supply of outside liquidity is never limited by a binding resource constraint.

The key friction of private outside liquidity is the following: We assume that it is the investor's private information whether she has a positive endowment in period one. Thus, investors cannot write enforceable contracts in $t=0$, which are contingent on whether they have a positive endowment in $t=1$. Because investors cannot contract in $t=0$, we will only consider their behavior form period $t=1$ onwards. Furthermore, we have to consider only those investors who have a positive endowment.

We assume that investors have no market power, and that they are indifferent between consuming in periods one and two. Their utility is given by $v\left(\hat{c}_{1}+\hat{c}_{2}\right)$, where $\hat{c}_{t}$ is her consumption in period $t$ and $v: \mathbb{R}^{+} \rightarrow \mathbb{R}$ is a strictly increasing function. Consequently, they are willing to invest their complete endowment $e_{1}$ as long as the gross return in $t=2$ is at least $e_{1}$.

\footnotetext{
${ }^{11}$ Observe that for suspension of convertibility to be an effective measure there must not be aggregate uncertainty about the actual fraction of consumers who withdraw early. Moreover, suspension of convertibility is also ineffective if withdrawing depositors are paid out by new depositors, see the extension of the D\&D setup to an overlapping generation setting by Qi (1994).
} 


\subsection{First-best with Outside Liquidity}

We now derive the new first-best allocation, given that outside liquidity is available in the interim period. The social planner's objective function, specified by the maximization problem (2), remains unchanged. The objective is maximizing the consumers' welfare, whereas investors' utility does not enter our welfare measure. However, we assume that even the social planner cannot transfer funds from investors to consumers without restrictions. Because investors' welfare does not directly enter into the objective function, we require that investors must be willing to participate 42 The aggregate transfer from investors to consumers in period one is denoted by $d_{1} \leq e_{1}$, and $d_{2}$ denotes the reverse transfer in period two. Investors' participation constraint is given by $d_{2} \geq d_{1}$. It is straightforward that this constraint will be binding in the optimum, i.e., $d_{1}=d_{2}$ will hold in the following.

The first-best program with outside liquidity is slightly different from the one in the previous section. We now explicitly consider the budget constraints in each period. The variable $I \in\left[0, e_{0}\right]$ again denotes the investment in the long asset, and an amount $e_{0}-I$ is invested in storage. Let $d$ denote the amount of interim liquidity (i.e., the amount of liquidity that is transferred between investors and consumers), where $d=d_{1}=d_{2} \leq e_{1}$.

The budget constraints for the two periods are given by

$$
\begin{aligned}
e_{0}-I+d & \geq \pi c_{1}(1)+(1-\pi) c_{1}(0), \\
R I & \geq \pi c_{2}(1)+(1-\pi) c_{2}(0)+d .
\end{aligned}
$$

Constraint (9) ensures that, in $t=1$, the payments to consumers do not exceed the sum of inside liquidity (storage) and interim outside liquidity. Constraint (10) ensures that, in $t=2$, the sum of payments to consumers and the repayment of interim outside liquidity does not exceed the return from investment in the long asset.

Proposition 1 (First-best). In the presence of outside liquidity, the consumers' firstbest consumption allocation is given by $c_{1}(1)=c_{2}(0)=R e_{0}$, and $c_{1}(0)=c_{2}(1)=0$. It is attained by choosing $I=e_{0}$ and $d=\pi R e_{0}$.

The fundamental insight of Proposition 1 is that the D\&D allocation, in which consumption levels in both periods are strictly less than $R e_{0}$, can strictly be improved

\footnotetext{
${ }^{12}$ In our setup, a comparison of consumers' and investors' utility does not appear meaningful. We are neither interested in the allocation of risk, nor in redistribution of wealth between the two groups of agents. We interpret the investor's participation constraint rather as a resource constraint that as a friction. It thus appears adequate to refer to the optimum as the "first-best".
} 
upon 13 The social planner can make full use of the productive long asset because the supply of liquidity in the interim period removes the need to invest in storage. In the model with outside liquidity, the trade-off between liquidity insurance (provided through the short-asset, i.e., inside liquidity) and return (long-asset) can be solved such that consumption is perfectly smoothed by making full use of the productive technology.

Observe that the first-best allocation is not unique if the endowment of investors strictly exceeds the amount that is given to impatient consumers in the interim period, $e_{1}>\pi R e_{0}$. Because early and late consumption are perfect substitutes for patient consumers, impatient consumers could receive some positive payment in $t=1$, as long as their total amount of consumption remains unchanged. Without loss of generality, we focus on the solution presented in Proposition 1 in the following, i.e., impatient consumers only consume late 14

\subsection{Efficient Banking}

We now show that the first-best allocation in the model with outside liquidity can be implemented by an institution that is reminiscent of a financial intermediary that signs demand-deposit contracts with consumers in period zero. In contrast to the situation without outside liquidity, a bank now only invests in the long asset and raises liquid funds in the interim period. It raises funds by issuing claims and selling them to investors. We will refer to those claims as debt 15

As in the D\&D setup, one may think of the banking sector as a contestable market. The assumption of free entry and the resulting perfect competition imply that financial intermediaries implies contracts that maximize the expected utility of consumers 16 Again, the law of large numbers is assumed to apply on the bank level, resulting in a gross return of $R$ on the long asset with certainty, and a fraction of early impatient consumers of exactly $\pi$.

Therefore, banks can implement the first-best in the following way (see also Figure 2): banks collect the total endowment $e_{0}$ of all consumers as deposits in period zero against the promise that consumers can withdraw $R e_{0}$ units at any time. In order to serve

\footnotetext{
${ }^{13}$ This result is reminiscent of the finding by Qi (1994), who shows that storage may be redundant in a overlapping-generation version of the $\mathrm{D} \& \mathrm{D}$ model.

${ }^{14}$ Notice that this allocation can be attained by choosing any $d \in\left[\pi R e_{0}, e_{1}\right]$.

${ }^{15}$ Notice that the bank could likewise issue equity claims. As we frame the problem as one of rollover, however, we refer to the claims as debt claims without giving a specific microeconomic reasoning why debt is preferred over equity.

${ }^{16}$ Alternatively, one may assume that the banking sector is a mechanism or a coalition of consumers that maximizes the consumers' expected utility.
} 
their obligations, banks invest all of the economy's $t=0$ endowment in the long assets, transforming them in $R e_{0}$ units in $t=2$. In the interim period, banks sell claims $d$ on their portfolio of long assets to investors. Because banks are assumed to be able to diversify the liquidity and the return risk, there is no adverse selection in the market for claims in the interim period. Therefore, the investors' participation constraint implies that banks can sell their claims at par. Banks will sell claims with a total value of $\pi R e_{0}$, and only impatient consumers withdraw early. The issuance of claims is equivalent to a rollover of debt, as the liability towards depositors is replaced by liabilities towards investors.

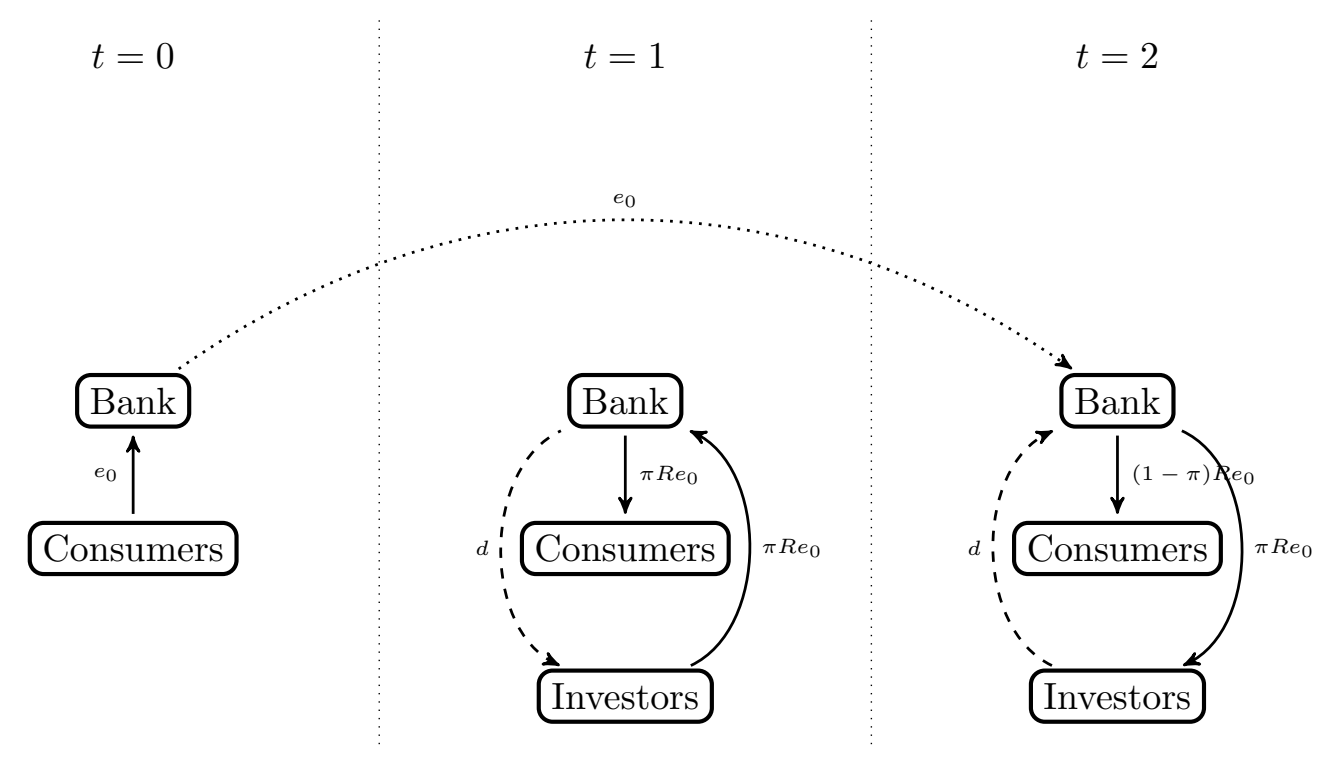

Figure 2: Private Outside Liquidity. The graph illustrates investment and the flow of goods (solid arrows) and claims (dashed arrows). Claims associated with demand-deposit contracts are not depicted. In $t=0$, consumers deposit their endowment $e_{0}$ at the banks. Banks invest the endowment in the long asset, transforming e $e_{0}$ units of the good into Re $e_{0}$ units. In the interim period, early consumers are served by selling claims d to investors. In $t=2$, banks redeem the claims of investors and repay investors and late consumers using the returns of the long asset.

Proposition 2 (Implementation of the first-best). The first-best allocation $c_{1}(1)=$ $c_{2}(0)=R e_{0}$ can be implemented in a demand deposit economy. Banks invest only in the long asset. Banks serve withdrawing consumers in the interim period by issuing claims on future returns and selling these to investors in exchange for outside liquidity.

The implementation of the first-best allocation thus involves privately produced assets. 
Instead of investing in storage in $t=0$, financial intermediaries issue claims on their future returns in the interim period. The proceeds from selling these to investors are used to serve withdrawing consumers. This allows intermediaries to increase the investment in the long asset and thus to promise higher payments to consumers.

As in the D\&D setup, the first-best allocation cannot be implemented by trade in a financial market in the interim period. The reason is somewhat different, however. In our model, the main reason why financial markets cannot implement the first-best is that consumers cannot insure themselves against idiosyncratic return risk. For such an insurance, contingent contracts between consumers or between consumers and investors are required, which are not feasible because of the unobservability of consumers' returns, liquidity needs and investors' endowments. For a detailed analysis, see the Appendix A. Because the idiosyncratic return risk restricts the benefits of side-trading, it can be interpreted as trading restriction in the sense of (Jacklin, 1987; von Thadden, 1998).

The fragility associated with this implementation will be discussed in the next section.

\section{Private Outside Liquidity and Rollover Risk}

In this section, we show that a bank may face a rollover freeze if it relies on raising liquidity by issuing claims in the interim period. It turns out that the efficient private provision of liquidity is inherently fragile. Therefore, banks might refrain from relying on outside liquidity. Instead, they might rely on the inefficient storage technology and offer the D\&D contract.

\subsection{Rollover Freeze}

Consider the subgame starting in the interim period, given that banks have invested the complete endowment in the long asset. In this subgame, consumers are endowed with a demand-deposit contract promising $R e_{0}$ units in either period, and banks issue claims on their future returns in order to serve withdrawing consumers. Consumers have the choice to withdraw early or to wait, and investors have the choice whether to buy claims on bank assets. In the previous section, we saw that there exists an efficient equilibrium of this subgame in which consumers do not run on banks and investors roll over the banks' debt. However, there are strategic complementarities between agents, giving rise to multiple equilibria. As in the $\mathrm{D} \& \mathrm{D}$ model, there is a strategic complementarity between consumers whether or not to withdraw early. In the model with outside liquidity, an additional strategic complementarity arises between investors concerning their decision whether to buy claims on bank assets and thus to roll over the banks' debt. 
Furthermore, there is also strategic complementarity across these two groups of agents. In the following, however, we will only focus on the strategic complementarity between investors.

In order to understand the rollover freeze, consider a situation in which no investor is willing to purchase bank claims. Let us first assume that only impatient consumers withdraw early. In this case, banks will need to liquidate a positive fraction $z=\min [\pi / \ell, 1]$ of their long assets at the inefficient rate $\ell R$ in order to serve impatient consumers with an amount of $\pi R e_{0}$ units. This liquidation implies that the bank will only be left with $(1-z) R e_{0}$ in $t=2$. Therefore, the bank will not have sufficient funds at hand in order to serve its patient customers or any investors in $t=2$. Therefore, an individual investor will not provide any liquidity in $t=1$, as banks will be insolvent in $t=2$. This implies that even if consumers behave diligently and do not run on the bank, a rollover freeze always constitutes an equilibrium.

This consideration also leads to the insight that the standard measures to prevent inefficient liquidation and thus financial crises, such as deposit insurance (DI) or suspension of convertibility (SoC), become ineffective. The reason is that these policies are only targeted at breaking the strategic complementarity between depositors - they are concerned with the demand for liquidity, but not with its supply. A DI may keep patient consumers from running on banks, but a bank run is not the only way a bank can become illiquid and insolvent once a bank relies on outside liquidity. Banks may in fact experience a rollover freeze as the deposit insurance does not alter the strategic complementarity between investors. Moreover, SoC is also ineffective. By suspending convertibility, banks can limit the amount they pay out to early consumers, which induces stability in the D\&D model because it eliminates the need for liquidation. However, if banks rely on outside liquidity, this measure does not prevent liquidation in case of a rollover freeze, inducing consumers to run.

Lemma 1. In the $t=1$ subgame, a rollover freeze by investors constitutes a Nash equilibrium. Moreover, a rollover freeze may occur independently of whether there is a bank run or not, and irrespectively of the existence of a credible deposit insurance or of banks committing to suspend convertibility.

In the following, we show that the fact that there may be a rollover freeze in $t=1$ makes banks either refrain from providing the efficient level of liquidity or it will expose the economy to the rollover risk. In the latter case, the economy will be fragile despite DI or SoC. 


\subsection{Inefficient Liquidity Provision}

Because the subgame of the interim period has an efficient as well as an adverse equilibrium, the whole game (starting in period zero) has at least one additional, inefficient subgame-perfect Nash equilibrium. While there might be a continuum of equilibria, we are interested in the generic case where investors coordinate on a rollover freeze. In a subgame-perfect Nash equilibrium, consumers and banks anticipate not being able to raise any outside liquidity in the interim period. Given that outside liquidity is not available in the interim period, banks have to rely on storage again. The constraint efficient allocation is given by the Diamond-Dybvig allocation described in Section 2.2 .

Proposition 3. The model has a subgame-perfect Nash equilibrium in which investors do not roll over bank debt, consumers do not run on banks, and banks implement the Diamond-Dybvig consumption allocation, given by $c_{1}(1)=c_{1}^{D D}$ and $c_{2}(0)=c_{2}^{D D}$, and $c_{1}(0)=c_{2}(1)=0$.

We have seen that if banks rely on raising outside liquidity by issuing claims on their future return, they are exposed to the risk of investors coordinating on a rollover freeze. The most efficient allocation entails full exposure to the rollover risk resulting from the coordination problem. If banks fear a rollover freeze, they might completely shy away from relying on outside liquidity, rather implementing the less efficient D\&D allocation.

The reasoning in Proposition 3 is in fact very similar to the argument in the $\mathrm{D} \& \mathrm{D}$ model that if a bank run was expected in $t=1$, consumers would not be willing to deposit their endowment in the bank in $t=0$. However, it is important to notice that the adverse equilibrium cannot be eliminated by the standard measures (DI, SoC) in our model. This is due to the key friction of non-contractible private outside liquidity. One may assume that the government offers a credible DI or banks may commit to SoC. In our setup, this will not eliminate the fragility associated with the efficient provision of liquidity. In fact, if there is no credible DI, a third equilibrium may exist in which investors would not roll over bank debt and investors would run on the bank, which is why no bank is founded in the first place. In turn, if there is a credible DI, this equilibrium does not exist. However, the DI is tested in the equilibrium of Proposition 3 and may be costly for the institution providing it.

Finally, Proposition 3 can be seen as an argument for why liquidity provision by banks may be limited in general. We argue hat efficient liquidity provision rests on reliance on outside liquidity. However, privately produced assets may not be able to ensure the provision of outside liquidity. Due to the rollover risk associated with privately produced assets, financial intermediaries may thus not be able to implement the optimal 
allocation. This line of argument stands in contrast to models arguing that banks are especially suited to provide banking services because of their fragile capital structure (Calomiris and Kahn, 1991; Diamond and Rajan, 2001). In our setup, the fragility in the interim period can cause banks to refrain from supplying liquidity in an optimal fashion.

\subsection{Fragility}

Until this point, we have tied our hands by assuming that investors cannot coordinate their behavior on something that is not observed or not initially contractible. Formally, this means that investors cannot play a strategy by which they condition their action on a public signal that is only revealed in the interim period. This implies that a rollover freeze will never occur in a subgame-perfect Nash equilibrium in pure strategies. Either banks successfully rely on outside liquidity because they know that a rollover will be successful, or they anticipate a rollover freeze and rely on the storage technology. In equilibrium, the rollover "risk" is degenerate, as it either occurs with a probability of zero, or it occurs with a probability of one, but has no effect 17

We now want to consider a setup where investors can coordinate on a rollover freeze. The notion of coordination problems in the tradition of the D\&D model is that depositors decide in the interim period whether to withdraw, thus coordinating on whether to run on the bank only after the investment decision has been made. Formally, the concept of subgame perfection requires agents to choose a strategy in period zero. Therefore, uncertainty about the action in $t=1$ can only prevail if there exists a public signal upon which agents can condition their action. A popular illustration of such a coordination device is the concept of sunspots 18

We adopt this notion and assume that with some exogenous probability $p \in(0,1)$ a sunspot occurs, and investors play a strategy that prescribes not to roll over the banks' liabilities in case of this sunspot 19 We restrict our attention to the two extremes where the probability of a rollover freeze is either close to one or close to zero.

Proposition 4. As the probability of a rollover freeze converges to one, i.e., $p \rightarrow 1$, the optimal investment converges towards the Diamond-Dybvig case, $I(p) \rightarrow I^{D D}$. Further-

\footnotetext{
${ }^{17}$ There exists no equilibrium in which investors play mixed strategies and banks rely on rollover. While this might seem strange, it is worth mentioning that investors play a weakly dominated strategy in the "rollover equilibrium". As soon as we introduce marginal net profits for investors, rollover stops being weakly dominated and an equilibrium in mixed strategies arises.

${ }^{18}$ See Cooper and Ross $(1998)$ for an analysis of the D\&D setup with sunspots.

${ }^{19}$ We do not model the underlying reason for the occurrence of these sunspots, and if we did, their occurrence would probably depend upon the banks' behavior.
} 
more, there exists a threshold $p_{\ell} \in(0,1)$ such that for $p \leq p_{\ell}$, it is optimal fully to rely on private outside liquidity storage, $I^{*}(p)=e_{0}$.

For the proof of Proposition 4, see the Appendix. The result, however, is very intuitive as it rests on the insight of the following trade-off: On the one hand, efficiency can be attained by choosing high investment in the illiquid but profitable long-term technology. Because banks thereby rely on outside liquidity, this is associated with a high rollover risk. On the other hand, stability can be attained if banks are not exposed to rollover risk. To this end, banks make use of the storage technology and thus rely on inside liquidity. In other words, the trade-off is between strong maturity mismatch and narrow banking.

If the sunspot probability $p$ is sufficiently high, banks will implement the $\mathrm{D} \& \mathrm{D}$ allocation. Banks and consumers know that each unit of early consumption that is not covered by investment in the storage technology has to be raised by liquidating long assets in case of a rollover freeze. Therefore, banks will finance every unit of early consumption by using inside liquidity and the optimal allocation under this constraint is the D\&D allocation. In contrast, if the probability of a rollover freeze is sufficiently small, banks choose full exposure to rollover risk by only investing in the long asset, and implement a consumption level of $R e_{0}$ for both consumer types. This implies that banks have to engage in substantial liquidation in case of a rollover freeze, but given that this risk is very low, they are willing to accept this risk.

It is worth noticing that even if a rollover freeze occurs with a positive probability, it may still be optimal that banks fully rely on outside liquidity. In this case, the economy is inherently fragile and a financial crisis may unfold in equilibrium if investors coordinate on a rollover freeze.

\section{Public Outside Liquidity}

In Section 3, we showed that optimal liquidity management does not rely on inside liquidity, but rather on outside liquidity. Building on this, Section 4 revealed that the efficient allocation can be implemented by banks issuing private claims and relying on the rollover of debt. However, outside liquidity in exchange for privately produced assets is associated with a rollover risk. The anticipation of a rollover freeze can lead to inefficient investment choices ex-ante. We now analyze how this friction could be overcome. In particular, we ask whether the government can mitigate the problem by providing liquidity.

In general, a government has the ability - unlike private agents - to commit future 
income via taxation or money creation. This makes claims against a public authority inherently safer than claims produced by the private sector. In the first part of this section, we therefore assume that the government never defaults. In this case, we show that the government can increase welfare by issuing a public claim that can be used by banks to manage liquidity. In the second part of this section, we relax the assumption that the government cannot default and show that the benefits from public provision of liquidity may vanish.

\subsection{Liquidity Management and Government Bonds}

Let us assume that the government never defaults. Consider the following mechanism in which the government provides liquidity by issuing a government bond (Figure 3): In $t=0$, consumers deposit their endowment $e_{0}$ at a bank in exchange for a demanddeposit contract allowing the consumer to withdraw $R e_{0}$ in either period. Banks receive government bonds that promise a payment of $b$ units by the government in $t=2$. In exchange for the $b$ government bonds, banks write a debt contract with the government, promising to pay $d$ units to the government in $t=2$. Banks and government will lend and borrow such that $d=b \geq \pi R e_{0}$. Effectively, banks are expanding their balance sheets by an amount of $b$.

In $t=1$, banks sell $\pi R e_{0}$ units of government bonds to the investors and use the resulting liquidity to serve withdrawing consumers. In $t=2$, the government has due gross liabilities of $b$ units, necessary to redeem the government bonds. An amount of $\pi R e_{0}$ is paid to investors. The difference of $b-\pi R e_{0}$ units is a gross liability towards banks, resulting from the government bonds they did not sell to investors in $t=1$. However, the banks also owe $d=b$ units to the government. Therefore, they have a net liability of $\pi R e_{0}$ units towards the government. The banks have an overall return of $R e_{0}$ from the long assets which is used to pay out $(1-\pi) R e_{0}$ units to the patient consumers and $\pi R e_{0}$ to the government.

Proposition 5. If the government provides government bonds in $t=0$, the banks are able to implement the first-best consumption allocation, given by $c_{1}(1)=c_{2}(0)=R_{0}$ and $c_{1}(0)=c_{2}(1)=0$. Furthermore, the rollover risk is eliminated and the economy has a unique equilibrium.

By expanding their balance sheet, the banks implement the first-best allocation while the rollover risk is completely eliminated. Even if all other investors refused to buy government bonds, this would not influence the incentives of an individual investor. Public outside liquidity eliminates the coordination problem concerning the supply of 


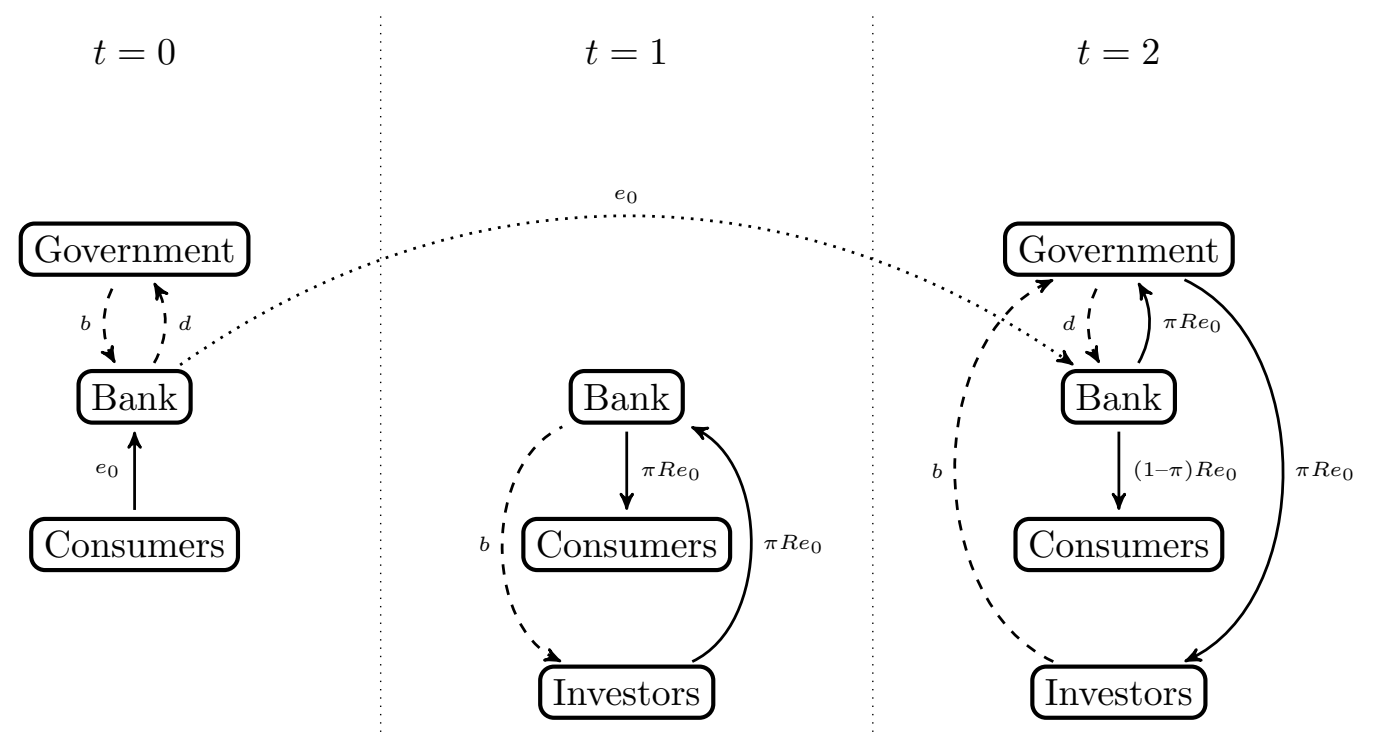

Figure 3: Public Outside Liquidity. The graph illustrates investment and the flow of goods and claims. In this graph, we assume that $b=d=\pi e_{0} R$. The dotted arrow denotes the investment in assets and thus the "transfer" of goods between periods. The solid arrows denote the flow of goods. The dashed arrows denote the flow of net claims. For simplicity, the claims of consumers towards banks (resulting from the demand-deposit contracts) are left out.

liquidity by investors. Note though that public liquidity provision as described does not address the coordination problem between consumers concerning their withdrawal decisions. However, given that there is public outside liquidity, a bank run equilibrium can be eliminated by the standard measures, i.e., by introducing a deposit insurance or allowing banks to suspend convertibility. This is important as we saw in the previous section that these measures are ineffective as long as the rollover problem is not addressed, but in this context they are effective at eliminating the coordination problem.

The central reason for the stability is that by assumption the government's solvency, unlike that of a bank, does not depend on the behavior of investors. This eliminates any strategic considerations of investors when deciding to purchase government bonds in the interim period. Therefore, multiplicity of equilibria vanishes once government securities are used for liquidity management 20

Observe that there are alternative implementations of the first-best allocation to the

\footnotetext{
${ }^{20}$ This is reminiscent of how multiplicity of equilibria is eliminated in the Kiyotaki and Moore (1997) model when government bonds are introduced (see p. 515 in Tirole, 2010).
} 
one shown in Figure 3. There are two obvious alternatives. First, the government could insure all current and future bank liabilities ex-ante. Second, the government could provide liquidity itself in the interim period. Both mechanisms are equivalent in terms of the results in our setup, as they also eliminate the fragility and thereby enhance efficiency. However, we argue that both alternatives may not be equally desirable as they may be more problematic in a richer setup in which other issues such as agency problems may arise. Insuring bank liabilities may give rise to certain risks on behalf of the bank (e.g., risk-shifting) and creditors (e.g., weak disciplining effects). Moreover, if the government actively manages liquidity by lending directly to banks when they need funds, i.e., in a crisis, this may lead to excessive maturity mismatch as in, e.g., Farhi and Tirole (2012). We discuss these two issues in more depth in Section 6.

\subsection{Government Solvency}

So far, we have made the extreme assumption that the government is always able to repay its debt, irrespectively of what investors do and of whether there is a banking crisis. This assumption gives government bonds the important characteristic of being immune against rollover risk. We now relax this assumption in two different ways. First, we allow the government to default with some exogenous probability. We show that, in this case, public liquidity provision may still be optimal. Second, we assume that the government's ability to repay debt is endogenous and depends on the performance of the banking sector. In this case, the benefits from public liquidity provision vanish.

Assume first the government defaults with some positive probability which is given exogenously. This is not necessarily detrimental to efficiency and stability. Under the condition that investors are risk-neutral, and that the government's solvency is only revealed after $t=1$, the optimal allocation could still be implemented. Under these conditions, the value of government bonds is still independent of the behavior of the investors. Thus, even if there is an exogenous default probability, there is no risk of a coordination failure between investors. Government bonds would be traded at the fair price (under par), and the government debt must be chosen such that its expected repayment equals the banks' liabilities towards the government. If we require the debt contracts between the banks and the government to be budget-balanced in expectation, the implementation could be as follows: Assume that the government defaults with probability $\rho$ and repays nothing in this case. The government still holds a claim of $d=\pi R e_{0}$ against the banks, whereas the banks hold claims with a face value of $b=$ $d / \rho=\pi R e_{0} / \rho$ against banks. When selling these claims to investors, the fair value is given by $d=\pi R e_{0}$. 
Let us now relax the exogeneity assumption and go to the other extreme. Assume that the government can only repay its debt if banks are solvent and thus fully serve their liabilities towards the government $d$. We thus relax the assumption that the government has access to exogenous funds, e.g., via taxation. In this setup, all features of the setup without government bonds reappear. The equilibrium of the $t=1$ subgame still exists in which investors roll over debt, and one equilibrium where they do not. The whole game thus still has a subgame-perfect equilibrium that implements the first-best. However, this equilibrium is not unique - there also exists an equilibrium of the $t=1$ subgame where a rollover freeze is accompanied by a government default. This induces banks to refrain from implementing the optimal allocation and the D\&D allocation is implemented instead. In this case, the public provision of liquidity cannot help to overcome the coordination problem. The fragility of an economy in which both the solvency of banks and that of the government are endogenous and interdependent is discussed in more detail in Luck and Schempp (2014b).

\section{Liquidity Regulation in Basel III}

Our model shows that the government should use its unique ability to ensure efficient liquidity management by issuing government securities that are held by financial intermediaries. This becomes necessary because the efficient liquidity management relies on the provision of non-contractable liquidity by private agents. By issuing government bonds, the government can prevent private agents from coordinating on an equilibrium in which liquidity supply breaks down. This is a simple way to stabilize the financial sector and, at the same time, to circumvent the undesired consequences that might arise if the regulator directly insured bank liabilities or provided emergency liquidity in case of a financial crisis. In our model, financial intermediaries voluntarily hold government bonds to manage liquidity. However, in a richer model, banks may prefer to hold privately produced assets if these assets promise a higher return than government securities. In this case, a regulator might optimally force banks to hold government securities in order to enhance stable liquidity provision.

In the following, we relate our findings to the regulatory treatment of liquidity risk in the context of prudential supervision. Our model can shed light on the economic consequences of some recently proposed regulation. The Third Basel Accord (Basel III) introduces a new assessment and regulation of liquidity risk by defining two minimum standards of funding liquidity (see Basel Committee, 2010). The two central measures are the Liquidity Coverage Ratio (LCR) and the Net Stable Funding Ratio (NSFR). 
The LCR requirement aims to ensure that a bank can withstand a "significantly severe liquidity stress scenario" with a horizon of 30 days. It requires a bank to have a sufficient stock of liquid assets in order to cover its liquidity needs during the next month. The objective of the NSFR requirement is to ensure stable funding over a one-year horizon. It requires a bank to have a sufficient amount of equity, long-term debt, and other "stable" funding to finance its stock of illiquid assets during the next year.

We acknowledge that both measures can in principle be useful tools to reduce the fragility arising from maturity transformation. Both the LCR and NSFR address the fundamental problem of maturity mismatch, resulting from short-term liabilities and long-term illiquid assets. In the light of our model, however, the regulatory details are not strict enough, as the inherent fragility of privately produced liquidity is not adequately addressed. Banks face two types of self-fulfilling liquidity problems: On the asset side, seemingly liquid, privately produced assets might turn illiquid 21 On the liability side, seemingly stable wholesale and deposit funding might evaporate in a similar fashion. In particular, the ability to borrow against privately produced assets is limited. As our model showed, government bonds play a unique role as they can eliminate an equilibrium in which private agents coordinate on not supplying liquidity. We argue that the LCR and NSFR underestimate the risk of such adverse equilibria and do not sufficiently distinguish between private and public assets. After studying the two measures separately, we will illustrate their similarity and their common problems.

\subsection{Liquidity Coverage Ratio (LCR)}

Basel III requires the LCR, defined as the ratio of High Quality Liquid Assets (HQLA) and the (hypothetical) total net cash outflows over the next 30 calendar days, to be above 122 Thus, the LCR sets a lower bound for the stock of liquid assets, conditional on a bank's (expected) cash flows. "Total net cash outflow" is defined as the maximum of "total expected net cash outflow" and " $25 \%$ of total expected cash outflow". In this context, "expected" denotes a scenario of a combined idiosyncratic and marketwide shock that entails (among others) a partial run-off of retail deposits and a partial reduction in unsecured wholesale funding and secured short-term financing.

The definition of HQLA is such that privately produced assets can partly be used to satisfy the LCR requirement. HQLA can be divided into two categories: Level 1 assets are cash, central bank reserves, and government bonds with $0 \%$ risk-weight. Level 2

\footnotetext{
${ }^{21}$ Luck and Schempp (2014a) provide a more detailed explanation of why private information and limited arbitrage capital can cause liquidity problems in markets for privately produced assets.

${ }^{22}$ For details on the LCR, see Basel Committee (2013).
} 
assets can again be divided in two sub-categories, Level $2 \mathrm{~A}$ and Level $2 \mathrm{~B}$ assets. A minimum haircut of $15 \%$ has to be applied to all Level 2 assets, which is supposed to capture their devaluation in a crisis scenario. After applying this haircut, Level 2 assets must not make up more than $40 \%$ of the whole stock of HQLA. Level 2A assets include government bonds with risk weights below $20 \%$ as well as corporate debt securities (including commercial papers) and covered bonds with a rating of at least AA-. Level 2B assets also include Residential Mortgage Backed Securities (RMBS) with ratings of at least AA, corporate debt securities with ratings of at least BBB-, and common equity shares which are constituent of a major stock index. These assets are subject to a haircut between $25 \%$ and $50 \%$ and must not make up more than $15 \%$ of the stock of HQLA ${ }^{23}$

In addition to these requirements, the Basel Committee specifies liquidity requirements of eligible assets in the following way: Level 2 assets must be

"traded in large, deep and active repo or cash markets characterised by a low level of concentration [and] have a proven record as a reliable source of liquidity in the markets (repo or sale) even during stressed market conditions (ie maximum decline of price not exceeding $10 \%$ or increase in haircut not exceeding 10 percentage points over a 30-day period during a relevant period of significant liquidity stress)."24

The requirements for Level 2 assets are thus defined in terms of their past and present liquidity. The underlying notion seems to be that an asset's past and present liquidity predicts its future liquidity. This is particularly evident in the condition that an asset's value must have been stable in a "period of significant liquidity stress". However, even if an asset stayed liquid during a past period of liquidity stress, this does not guarantee its future liquidity.

Under the currently proposed regulation, Level 2 assets can constitute up to $40 \%$ of the required assets to ensure short-term liquidity. This portfolio may consist exclusively of claims on the private sector, like corporate loans, MBS, and ABS. A stress scenario like the one in our model shows that such assets are not well suited to ensure the liquidity of banks. If banks rely too much on private assets, the economy might experience a run equilibrium in which private agents coordinate on a liquidity freeze. The price of seemingly safe and liquid claims on private institutions might drop substantially and in a fashion that is not predictable by their prior performance. Such an equilibrium can be ruled out if banks hold a sufficient stock of government bonds to cover the collapse of

\footnotetext{
${ }^{23}$ Note that they must also be included of the $40 \%$ cap of all Level 2 assets.

${ }^{24}$ Basel Committee (2013).
} 
short-term funding. In order to ensure the stable supply of non-contractable liquidity, only Level 1 assets should be allowed to for liquidity management.

\subsection{Net Stable Funding Ratio (NSFR)}

As a second measure of liquidity regulation, Basel III requires the NSFR to be above 1 . The NSFR is defined as the ratio of available stable funding (AFS) and required stable funding (RSF), both with a horizon of one year ${ }^{25}$ Thus, the NSFR sets a lower bound for the amount of stable funding, conditional on a bank's portfolio of illiquid assets and off-balance sheet exposures. ASF comprises capital, preferred stock, and liabilities with maturities of at least one year, but also deposits and wholesale funding with short or no maturity that are "expected to stay with the institution for an extended period in an idiosyncratic stress event." Liabilities of the latter categories have to be multiplied by an ASF factor of less than one. ASF aims to exclude unstable short-term funding, i.e., funding that might quickly be withdrawn or not rolled over. It excludes short-term wholesale funding, such as interbank lending, but includes customer deposits, because deposit insurance is supposed to make this funding appear stable.

RSF is a measure of a bank's illiquid asset portfolio. It is defined as the sum of the value of a bank's assets, multiplied by a specific RSF factor that is supposed to capture an asset's liquidity risk, plus a similarly weighted sum of the bank's off-balance sheet activities or potential liquidity exposures. An asset's RSF factor is lower the more liquid this asset is. Cash and securities with a maturity below one year have an RSF factor of 0\%; other securities and corporate bonds with good ratings have low, but positive RSF factors; other bonds, mortgages and loans have higher RSF factors, and other assets (particularly encumbered assets) have RSF factors of $100 \%$.

The notion behind the NSFR requirement is that the ASF serves a bank to finance its illiquid asset contained in the RSF in times of a liquidity crisis. Those assets not contained in the RSF are liquid and can thus be sold in order to compensate the "unstable" funding that might disappear in a crisis. However, the criticism concerning the specification of the LCR applies in a similar way to the specification of the NSFR, as it does not sufficiently consider the problem of self-fulfilling liquidity dry-ups. The definition of RSF excludes several types of (private) assets that might turn illiquid in a crisis and thus also require stable funding. Moreover, the definition of ASF relies on a crisis scenario in which short-term funding is partly assumed to be stable. Our model shows that non-contractable short-term funding by private agents is needed for efficient intermediation, but these agents can coordinate on a liquidity dry-up. While insured

\footnotetext{
${ }^{25}$ For details on the NSFR, see Basel Committee $(2010)$.
} 
demand-deposits could be considered as stable funding, this does not apply to wholesale funding because investors could coordinate on a freeze of if banks do not hold a sufficient stock of government bonds.

\subsection{Comparison}

Although the definitions of the LCR and NSFR appear quite different on first sight, their time horizon is the only distinct difference. To illustrate this point, let us consider a stylized bank balance sheet. Assume that the bank's assets can be divided into a portfolio of liquid and a portfolio of illiquid assets, and that the liability side consists of short-term debt, long-term debt, and equity, see Figure 4.

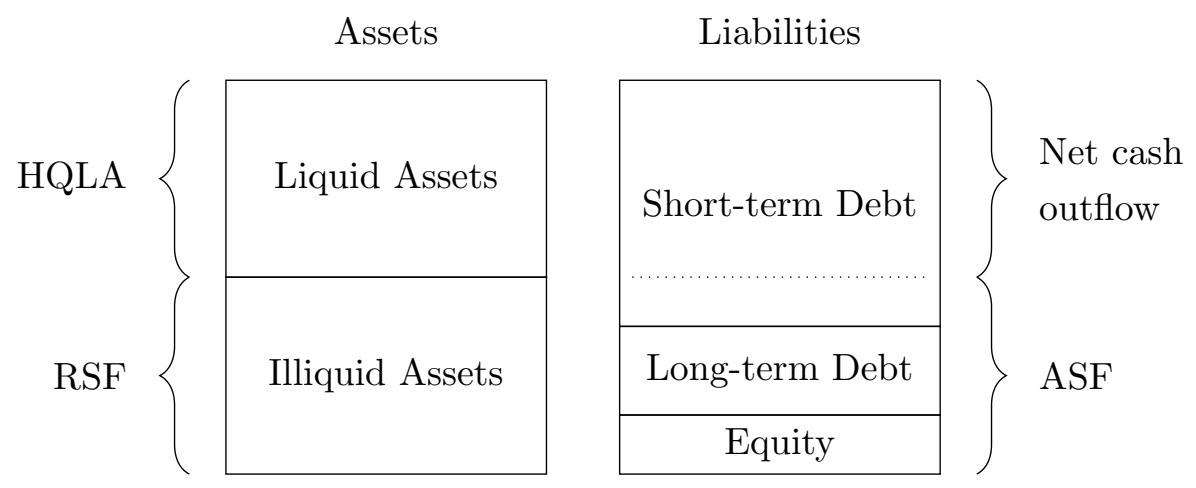

Figure 4: Schematic representation of the bank balance sheet under the assumption that LCR and NSFR were defined for the same time horizon.

For a moment, let us ignore the different time horizons of the two liquidity requirements and pretend that all quantities have been defined for the same horizon. In this case, the left side of the balance sheet consists of HQLA and RSF, because the illiquid assets are exactly those that require stable funding. Which asset is considered to be liquid or illiquid is determined by the scenario of stress that is specified by the regulator. On the liability side, the scenario specifies which kind of funding is expected to disappear and which is expected to stay during a crisis. The expected net cash outflow is defined by the difference between the inflow and outflow of short-term debt in the specified scenario; it thus measures the expected change in the bank's short-term liabilities. The part of short-term funding which (in the relevant scenario) is not assumed to disappear, together with long-term debt and equity, forms the ASF. Because total liabilities are necessarily equal to total assets, the LCR and the NSFR requirements are equivalent: HQLA exceed expected net cash outflow if and only if ASF exceeds RSF. It follows that the two measures only vary in their time horizon. 
The two main criticisms thus apply similarly to both liquidity measures: First, the definition of HQLA is too broad, and the definition of RSF is too restrictive. Second, the definition of the stress scenario appears quite ad-hoc and underestimates the severity of self-fulfilling liquidity crises. These two aspects are strongly interconnected: In our model, we showed that banks optimally rely on the future provision of liquidity, but since this is not contractible initially, investors might coordinate on not providing this liquidity. Such adverse equilibria can only be ruled out if the bank's balance sheet is structured such that disappearance of non-contractible funding can be compensated by selling liquid assets. We postulate that banks should cover this unstable funding by holding a sufficient stock of government bonds, and that the government should issue a sufficient amount of bonds for this purpose.

In our model, banks optimally expand their balance sheet by holding government bonds, and taking on liabilities with the same maturity towards the government. This increases the ASF as well as the stock of HQLA. Using the notion of Brunnermeier et al. (2013), this eliminates the banks' the liquidity mismatch. We argue that holding government bonds is the only way of eliminating the liquidity mismatch which is compatible with efficient liquidity provision. Because private assets are subject to self-fulfilling liquidity dry-ups, private assets cannot eliminate the liquidity mismatch.

The 2007-09 financial crisis painfully revealed the fragility associated with private liquidity production. Neither the regulator nor market participants suspected that the ABCP market or the repo market, which were both backed by collateral such as ABS, could turn illiquid. As a consequence, the funding of institutions that were exposed to subprime mortgage risk broke down completely, until public liquidity support was provided. The same applied to institutions that held these assets off-balance sheet, but granted liquidity guarantees to their off-balance sheet vehicles.

However, it would be wrong to conclude that the regulator only needs to tighten the regulation on those assets that turned out to be problematic in the recent crisis. Any privately produced asset might turn illiquid, and any privately supplied liquidity may evaporate. Whenever liquidity management relies on the provision of non-contractible resources in future, liquidity regulation should be restrictive.

\section{Conclusion}

The paper has two main results: First, liquidity management with privately produced assets is either inefficient or associated with rollover risk, which makes an economy inherently fragile. Second, financial intermediaries can implement the optimal allocation 
by using government bonds.

In the absence of public liquidity, financial intermediaries face a trade-off between high investment, which goes along with high rollover risk (high level of illiquid, but profitable long-term investments and low level of storage), and low investment, which comes with low rollover risk (low levels of profitable long-term investments and high level of storage). For the case of the 2007-09 financial crisis, our model suggests that intermediaries chose high investment levels that created a strong maturity mismatch. In the run-up to the crisis, financial intermediaries transformed long-term real investments into short-term securities, thereby aiming at making them liquid. E.g., illiquid assets like ABS and MBS (which are securitized long-term real investments) were transformed into shortterm securities such as ABCP. In the crisis, however, these short-term securities stopped being liquid and adverse consequences of the large-scale maturity mismatch realized.

Importantly, the rollover risk in our model is different from the traditional bank run problem in the style of Diamond and Dybvig (1983). In D\&D, the bank run problem can be addressed by contracting in the initial period, e.g., by implementing a deposit insurance or allowing for a suspension of convertibility. In contrast, the rollover risk in our model cannot be eliminated in such a way because this would require contracting with a party that is not available initially. The problem originates from the friction that investors cannot commit initially to provide liquidity later. Their endowment does not realize before the time at which financial intermediaries need liquid funds. This makes liquidity management with privately produced assets inherently fragile.

In the second part, we demonstrate how liquidity management with government securities can improve the efficiency and stability of an economy. The government has the unique ability to commit future resources via taxation. Therefore, government securities are - in comparison to privately produced assets - less prone to coordination failures, i.e., less exposed to rollover risk. This property makes public outside liquidity superior to private outside liquidity.

Our paper thereby also contributes to the following basic but yet unresolved question: How should a public authority deal with liquidity provision? The traditional view since Bagehot (1873) is that a government should lend to illiquid but solvent institutions at high rates, while refusing to lend to insolvent institutions. The implementation of this principle might not be straight forward. That is, it may generally be problematic to identify whether an institution is illiquid or insolvent (see, e.g., Rochet and Vives, 2004). Moreover, Farhi and Tirole (2012) point out that if a government commits to intervening in case of liquidity needs, a collective moral hazard may give rise to an overall excessive maturity mismatch in an economy. 
Our paper discusses a different approach to this problem. We find that the government should ensure efficient liquidity management by issuing government securities that should be held by financial intermediaries. This is a simple way of circumventing the undesired consequences that may arise when the regulator insures bank liabilities or provides emergency liquidity in case of a financial crisis. In our model, financial intermediaries are in fact always willing to hold government bonds to manage liquidity. However, in a richer model, banks may prefer to hold privately produced assets if these assets promise a higher return than government securities. In this case, a regulator might optimally force banks to hold government securities in order to enhance stable liquidity provision.

We thereby reach out to the political debate about which types of assets should be allowed for liquidity management from a regulatory perspective. Basel III introduces the Liquidity Coverage Ratio (LCR) and the Net Stable Funding Ratio (NSFR) as a measures and requirements to ensure a bank's short-term and medium-term liquidity in a stress scenario. However, banks can partly use assets originated by the private sector in order to satisfy this requirement. We argue that this may be a severe source of systemic risk: once liquidity evaporates from the financial sector, these types of assets may cease to be liquid as well. Therefore, these assets might not be helpful to cover short-term liabilities and thus to prevent self-fulfilling crises. 


\section{References}

Allen, Franklin, and Douglas Gale (1998). "Optimal Financial Crises". The Journal of Finance LIII.4, pp. 1245-1284.

(2000). "Financial Contagion". Journal of Political Economy 108.1, pp. 1-33.

Bagehot, Walter (1873). Lombard Street: A Description of the Money Market. London, UK: H.S. King.

Barro, Robert J. (1974). "Are Government Bonds Net Wealth?" Journal of Political Economy 82.6, p. 1095.

Basel Committee - Basel Committee on Banking Supervision (2010). Basel III: International Framework for Liquidity Risk Measurement, Standards and Monitoring. December. Basel: Bank for International Settlement.

Basel Committee - - (2013). Basel III: The Liquidity Coverage Ratio and Liquidity Risk Monitoring Tools. January. Basel: Bank for International Settlement.

Bhattacharya, Sudipto, and Douglas Gale (1987). "Preference Shocks, Liquidity and Central Bank Policy". In: New Approaches to Monetary Economics, Cambridge University Press, ed. by W. Barnett, and K. Singleton. Cambridge University Press, pp. 69-89.

Bolton, Patrick, Tano Santos, and Jose A. Scheinkman (2011). "Outside and Inside Liquidity". Quarterly Journal of Economics 126.1, pp. 259-321.

Brunnermeier, Markus K. (2009). "Deciphering the Liquidity and Credit Crunch 20072008". Journal of Economic Perspectives 23.1, pp. 77-100.

Brunnermeier, Markus K., Arvind Krishnamurthy, and Gary Gorton (2013). "Liquidity Mismatch Measurement". Working Paper.

Bryant, John (1980). "A Model of Reserves, Bank Runs, and Deposit Insurance". Journal of Banking \& Finance 4.4, pp. 335-344.

Caballero, Ricardo J. (2010). "Sudden Financial Arrest". IMF Economic Review 58, pp. 6-36.

Calomiris, Charles, and Charles Kahn (1991). "The Role of Demandable Debt in Structuring Optimal Banking Arrangements". American Economic Review 81.3, pp. 497513.

Chari, VV, and Ravi Jagannathan (1988). "Banking Panics, Information, and Rational Expectations Equilibrium". The Journal of Finance XVIII.3, pp. 749-761.

Cooper, Russell, and Thomas W. Ross (1998). "Bank runs: Liquidity Costs and Investment Distortions". Journal of Monetary Economics 41.1, pp. 27-38.

Dang, Tri Vi, Gary B. Gorton, and Bengt Holmström (2013a). "Ignorance, Debt and Financial Crises". Working Paper. 
Dang, Tri Vi, Gary B. Gorton, and Bengt Holmström (2013b). "The Information Sensitivity of a Security". Working Paper.

Dasgupta, Amil (2004). "Financial Contagion through Capital Connections: A Model of the Origin and Spread of Bank Panics". Journal of the European Economic Association 2.6, pp. 1049-1084.

Diamond, Douglas W. (1997). "Liquidity, Banks, and Markets". Journal of Political Economy 105.5, pp. 928-956.

Diamond, Douglas W., and Philip H. Dybvig (1983). "Bank Runs, Deposit Insurance, and Liquidity". Journal of Political Economy 91.3, pp. 401-419.

Diamond, Douglas W., and Raghuram G. Rajan (2001). "Liquidity Risk, Liquidity Creation and Financial Fragility: A Theory of Banking". Journal of Political Economy 109.2, pp. 287-327.

(2005). "Liquidity Shortages and Banking Crises". Journal of Finance 60.2, pp. 615-647.

Farhi, Emmanuel, and Jean Tirole (2012). "Collective Moral Hazard, Maturity Mismatch and Systemic Bailouts". American Economic Review 102.1, pp. 60-93.

Farhi, Emmanuel, Mikhail Golosov, and Aleh Tsyvinski (2009). "A Theory of Liquidity and Regulation of Financial Intermediation". Review of Economic Studies 76.3, pp. 973-992.

Fecht, Falko (2004). "On the Stability of Different Financial Systems". Journal of the European Economic Association 2.6, pp. 969-1014.

Gale, Douglas (1990). "The Efficient Design of Public Debt". In: Public debt management: theory and history. Ed. by Rudiger Dornbusch, and Mario Draghi. Cambridge University Press.

Goldstein, Itay, and Ady Pauzner (2005). "Demand-Deposit Contracts and the Probability of Bank Runs". The Journal of Finance LX.3, pp. 1293-1327.

Gorton, Gary B., and G Ordoñez (2013). "The Supply and Demand for Safe Assets". NBER Working Paper No. 18732.

Gorton, Gary B., and George Pennacchi (1990). "Financial Intermediaries and Liquidity Creation". The Journal of Finance XLV.1, pp. 49-71.

Gourinchas, Pierre-Olivier, and Olivier Jeanne (2012). "Global Safe Assets". BIS Working Paper No. 399.

Greenwood, Robin, Samuel G Hanson, and Jeremy C Stein (2012). "A ComparativeAdvantage Approach to Government Debt Maturity". Working Paper.

He, Zhiguo, and Wei Xiong (2012). "Dynamic Debt Runs". Review of Financial Studies 25.6, pp. 1799-1843. 
Hellwig, Martin (1994). "Liquidity Provision, Banking, and the Allocation of Interest Rate Risk". European Economic Review 38.7, pp. 1363-1389.

- (2008). "Systemic Risk in the Financial Sector: An Analysis of the SubprimeMortgage Financial Crisis". Preprint of the Max Planck Institute for Research on Collective Goods Bonn No. 2008/43.

Holmström, Bengt, and Jean Tirole (1998). "Private and Public Supply of Liquidity". Journal of Political Economy 106.1, pp. 1-40.

- (2011). Inside and Outside Liquidity. Cambridge, MA: The MIT Press.

Jacklin, Charles J. (1987). "Demand Deposits, Trading Restrictions, and Risk Sharing". In: Contractual Arrangements for Intertemporal Trade. Ed. by Edward C. Prescott, and Neil Wallace. University of Minnesota Press, pp. 26-47.

Jacklin, Charles J., and Sudipto Bhattacharya (1988). "Distinguishing Panics and Informationbased Bank Runs: Welfare and Policy Implications". Journal of Political Economy 96.3, pp. 568-592.

Jordà, Òscar, Moritz HP. Schularick, and Alan M. Taylor (2013). "Sovereigns Versus Banks: Credit, Crises, and Consequences". NBER Working Paper No. 19506.

Kashyap, Anil K., Raghuram Rajan, and Jeremy C. Stein (2002). "Banks as Liquidity Providers: An Explanation for the Coexistence of Lending and Deposit taking". The Journal of Finance LVII.1, pp. 33-73.

Kiyotaki, Nobuhiro, and John Moore (1997). "Credit Cycles". Journal of Political Economy 105.2, pp. 211-248.

Krishnamurthy, Arvind (2010). "How Debt Markets Have Malfunctioned in the Crisis". Journal of Economic Perspectives 24.1, pp. 3-28.

Krishnamurthy, Arvind, and Annette Vissing-Jorgensen (2012). "The Aggregate Demand for Treasury Debt". Journal of Political Economy 120.2, pp. 233-267.

— (2013). "Short-term Debt and Financial Crises: What We Can Learn from US Treasury Supply". Working Paper.

Lagos, Ricardo (2006). "Inside and Outside Money Inside and Outside Money". Federal Reserve Bank of Minneapolis Research Department Staff Report 374 May.

Longstaff, Francis A. (2004). "The Flight-to-Liquidity Premium in US Treasury Bond Prices". Journal of Business 77.3, pp. 511-526.

Luck, Stephan, and Paul Schempp (2014a). "Banks, Shadow Banking, and Fragility". ECB Working Paper No 1726.

(2014b). "Sovereign Default, Bank Runs, and Contagion". Preprint of the Max Planck Institute for Research on Collective Goods Bonn No. 2014/15. 
Martin, Antoine, David Skeie, and Ernst-Ludwig von Thadden (2014). "Repo Runs". Review of Financial Studies 27.4, pp. 957-989.

Postlewaite, Andrew, and Xavier Vives (1987). "Bank Runs as an Equilibrium Phenomenon". Journal of Political Economy 95.3, p. 485.

Qi, Jianping (1994). "Bank Liquidity and Stability in an Overlapping Generations Model". Review of Financial Studies 7.2, pp. 389-417.

Rochet, Jean-Charles, and Xavier Vives (2004). "Coordination Failures and the Lender of Last Resort: Was Bagehot Right After All?" Journal of the European Economic Association 2.6, pp. 1116-1147.

Saint-Paul, Gilles (2005). "Fiscal Policy and Economic Growth: The Role of Financial Intermediation". Review of International Economics 13.3, pp. 612-629.

Schularick, Moritz (2014). "Public and Private Debt: The Historical Record (18702010)". German Economic Review 15.1, pp. 191-207.

Tirole, Jean. (2010). The Theory of Corporate Finance. Princeton University Press.

Uhlig, Harald (2010). "A Model of a Systemic Bank Run". Journal of Monetary Economics 57.1, pp. 78-96.

von Thadden, Ernst-Ludwig (1998). "Intermediated versus Direct Investment: Optimal Liquidity Provision and Dynamic Incentive Compatibility". Journal of Financial Intermediation 7.2, pp. 177-197.

Woodford, Michael (1990). "Public Debt as Private Liquidity". American Economic Review 80.2, pp. 382-388. 


\section{Appendix A Sub-Optimality of Financial Markets under Outside Liquidity}

Let us analyze the competitive equilibrium of an economy where consumers hold assets directly and trade on financial markets. In the D\&D model, the first-best cannot be achieved via financial markets because, in equilibrium, the competitive market prices give consumers investment incentives that do not induce the investment profile that optimally trades off early liquidity needs and the returns of the long asset. This inefficiency arises because consumers do not take into account the pecuniary externalities of their investment. This is induced by the friction of unobservable liquidity needs (unobservable types).

In our setup, pecuniary externality do not necessarily arise. The mere unobservability of the liquidity type itself does not impede the implementation of the first-best. In the absence of return risk, each consumer could privately invest his whole endowment in the long asset and sell claims on the asset in the interim period. The key frictions in our case are that, on the one hand, the return risk cannot be diversified on the individual level and, on the other hand, the unobservability of the risky return induces adverse selection, leading to inefficient liquidation. The liquidity type friction only intensifies the return risk friction.

The first-best can only be implemented if all resources are initially invested in the long asset. Furthermore, consumers must be perfectly insured against return risk. However, this insurance is only implementable with commitment in period zero. In a pure financial market economy with spot markets for claims on future returns, contingent contracts are not feasible. Therefore, the financial markets cannot implement an allocation that is efficient ex-ante. The non-diversifiable idiosyncratic return risk might also imply that consumers invest a positive fraction of their endowment in storage.

Moreover, the financial-market allocation might not even be efficient ex post, i.e., given the initial private investment. If all consumers in fact invest in the long asset privately, all impatient consumers have to either sell or liquidate their asset in the interim period. Since the return is unobservable, all assets have to be sold at the same price $R^{*}$. All impatient consumers with a return $R_{i}>R^{*} / \ell$ have an incentive to liquidate instead of selling claims, reducing the average quality in the market. The liquidation of projects is a form of adverse selection and constitutes an inefficiency ex post. Moreover, patient consumers with a return $R_{i}<R^{*}$ have an incentive to sell at price $R^{*}$ instead of waiting, thus exacerbating the adverse selection and inefficiency. 


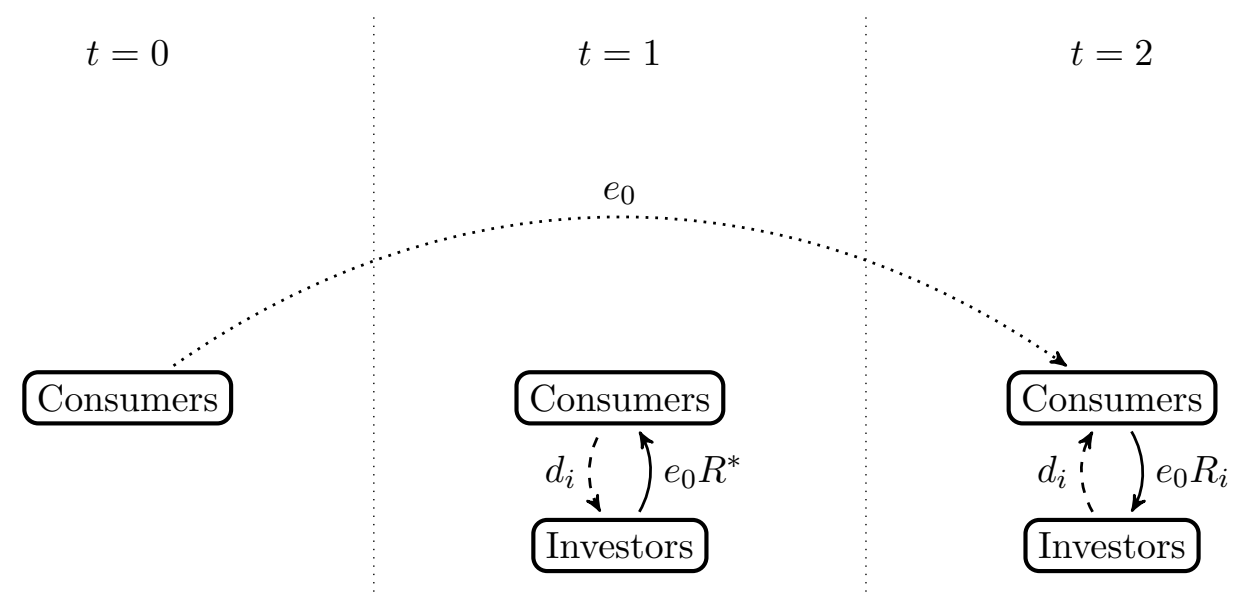

Figure 5: Financial Market. The graph illustrates investment and trade under the assumption that full investment in the long asset is chosen. In the interim period, the graph denotes the flow of goods and claims for a consumer who chooses to sell claims on the market. Notice that there are also agents who liquidate their assets or hold on to them until $t=2$ and thus do not interact with investors.

\section{Appendix B Sunspots: Optimal Contracts under Private Outside Liquidity}

Assume that there is a public signal in $t=1$ which we might call sunspot, following a Bernoulli distribution with success probability $p$. Assume further that investors play a pure strategy by which they base their rollover decision on this public signal. With probability $p$, all investors refrain from rolling over, and with probability $1-p$, all investors engage in rollover. We are now looking for the optimal consumption profiles of consumers, i.e., the optimal investment behavior of banks, and abstract from bank runs. The optimal contract between banks and consumers will be state-contingent, i.e., contingent on the sunspot, or equivalently, on the behavior of investors.

Define the investment threshold $I_{\ell}$ such that

$$
\ell u^{\prime}\left(\frac{e_{0}-I_{\ell}}{\pi}\right)=u^{\prime}\left(\frac{R I_{\ell}}{1-\pi}\right) \text {. }
$$

This threshold has the following interpretation: It is ex-post optimal to liquidate a positive fraction in case of a rollover freeze if and only if investment exceeds this threshold, $I>I_{\ell}$. Because $\ell<1 / R$, it holds that $I_{\ell} \in\left(I^{D D}, e_{0}\right)$, i.e., liquidation is not efficient ex post in a setup without outside liquidity (D\&D), but it is efficient if banks do not invest in storage and completely rely on rollover, but this investors coordinate on a rollover 
freeze.

For the contingency of rollover, the optimal contract includes perfect consumption smoothing through outside liquidity and no liquidation, $c_{1}=c_{2}=e_{0}-I+R I$. For the contingency of a rollover freeze, there is positive liquidation if $I>I_{\ell}$, and there is no liquidation if $I \leq I_{\ell}$. The optimal investment level $I$ is determined by the probability of the rollover freeze.

We first derive the optimal consumption allocation in case of a rollover freeze for a given investment level $I$. The optimization problem is given by

$$
\begin{aligned}
& \max _{c_{1}, c_{2}, z \in[0,1]} \pi u\left(c_{1}\right)+(1-\pi) u\left(c_{2}\right), \\
& \text { s.t. } \pi c_{1} \leq e_{0}-I+z \ell R I, \quad \text { and } \\
& \pi c_{1}+(1-\pi) c_{2} \leq e_{0}-I+z \ell R I+(1-z) R I .
\end{aligned}
$$

The aggregate budget constraint $(13)$ is always binding. There exists a threshold $I_{0}<I^{D D}$ such that for $I<I_{0}$ it holds that $z=0$ and the budget constraint for period one is not binding, leading to perfect consumption smoothing. For $I_{0} \leq I \leq I_{\ell}$ it holds that $z=0$, and the first period budget constraint is binding, implying that $c_{2}>c_{1}$. For $I>I_{\ell}$ it holds that $z(I) \in(0,1)$ such that

$$
\ell u^{\prime}\left(\frac{e_{0}-I+z \ell R I}{\pi}\right)=u^{\prime}\left(\frac{(1-z) R I}{1-\pi}\right) .
$$

We now have (implicitly) specified the optimal contingent consumption profiles given an investment level $I$. We now maximize over this investment level. We split the problem by looking at the maximizing level of investment within each of the two intervals $\left[I_{0}, I_{\ell}\right]$ and $\left(I_{\ell}, e_{0}\right]$. We can ignore the interval $\left[0, I_{0}\right)$ because it is dominated by $I_{0}$.

There exist two thresholds $p_{0}$ and $p_{\ell}, 0<p_{0}<p_{\ell}<1$, such that $I(p)=e_{0}$ iff $p \leq p_{0}$, and $I^{*}\left(p_{\ell}\right)=I_{\ell}$.

If $p \in\left(p_{0}, p_{\ell}\right)$, the optimal $I^{*}(p) \in\left(I_{\ell}, e_{0}\right)$, and $I^{*}$ and $z$ are determined by

$$
\begin{gathered}
0=\quad p\left[(z \ell R-1) u^{\prime}\left(\frac{e_{0}-I^{*}+z \ell R I}{\pi}\right)+(1-z) R u^{\prime}\left(\frac{(1-z) R I^{*}}{1-\pi}\right)\right] \\
+(1-p)(R-1) u^{\prime}\left(e_{0}+(R-1) I^{*}\right), \text { and } \\
\ell u^{\prime}\left(\frac{e_{0}-I+z \ell R I}{\pi}\right)=u^{\prime}\left(\frac{(1-z) R I}{1-\pi}\right) .
\end{gathered}
$$


If $p>p_{\ell}$, the optimal $I^{*}(p) \in\left[I^{D D}, I_{\ell}\right)$ and its level is determined by

$$
p\left[-u^{\prime}\left(\frac{e_{0}-I^{*}}{\pi}\right)+R u^{\prime}\left(\frac{R I^{*}}{1-\pi}\right)\right]+(1-p)(R-1) u^{\prime}\left(1+(R-1) I^{*}\right)=0 .
$$

For any $p \in\left(p_{\ell}, 1\right)$, it holds that $I^{*}(p) \in\left(I^{D D}, I_{\ell}\right)$. As $p \rightarrow 1$, it holds that $I^{*}(p) \rightarrow I^{D D}$. 